\title{
A Research on the Practical Teaching Mode of Computer in the Light of MOOC Concept
}

\author{
Qi Shen \\ Nanjing software institute \\ Jinling Institute of Technology \\ NanJing, China \\ shenqi@jit.edu.cn
}

\author{
Ruchan Dong \\ School of Software engineering \\ Jinling Institute of Technology \\ NanJing, China \\ ruchandong@jit.edu.cn
}

\begin{abstract}
To solve the problems existing in the traditional teaching mode, based on previous study of software talents training mode, this paper reforms practice teaching pattern of computer major courses referencing MOOC idea, flipping the classroom in order to guarantee the teaching period and design different practice teaching modules; implementing Online/Offline $\mathrm{O2O}$ teaching method so as to improve the quality of practice teaching; carrying out the multi-evaluation to have scientific assessment for practice teaching effect. The comparison result of teaching effect of the same course between the experimental class and other classes under traditional teaching model shows the reform effective.
\end{abstract}

Keywords-Practical Teaching Mode; Massive Open Online Course (MOOC); practice teaching pattern; flipping the classroom; multi-evaluation

\section{INTRODUCTION}

In the 21th century, the software industry in our country will gradually step into the period of maturation. In recent years, the service outsourcing industry has become a national development strategy. Creating a "world famous software city" is proposed by Nanjing Government for the purpose of responding to the national call in order to build a platform for featured software industrial groups and public software services, thus leading and driving the development of Jiangsu Province along and across Yangtse River by the leading and span development of software industry. With the rapid development of the software and service outsourcing industry, a large number of high-quality core talents with technology, management and international vision is required, thus improving the overall competitiveness of the software and service outsourcing industry.

As we all know, to a country, the construction of software talents training system, the level of software talents training and their employment condition determine the level and potential of its software industry and even the development of the whole information industry. However, currently the disparities between software engineering talents training and the market demand become prominent. Specifically, they are deficient in innovation and engineering practice ability, as

Foundation item:

(1) Research and practice on software talent training based on industryuniversity-research cooperation education mode (2015JYJG08).

(2)Research on innovative basic software talents industry-universityresearch cooperative training mode (2015JSJG161).

(3)Exploration of autonomic learning and innovation ability training in applicative talent majoring in computer under the mode of MOOC mixed teaching system(40714011). well as a weak sense of cooperation and so on. In recent years, a part of colleges in our country introduced foreign advanced education concept. Based on their own characteristics of running a school, they did a lot of practical researches in engineering education, which obtained certain achievements.

\section{RESEARCH FOUNDATION}

CDIO (Conceive, Design, Implement, Operate) is an engineering education concept that is established by four colleges including Massachusetts Institute of Technology, Chalmers University of Technology, Linkoping University and Royal Institute of Technology in the international engineering education cooperation project jointly developed by twenty-three universities in the world. As an education concept and methodology system to guide the reform in the cultivation mode of engineering talents, and as a kind framework system of curriculum design, CDIO conforms to the general rule of the cultivating modern engineering and technical talents, which cultivates the students' engineering ability carried by the conception, design, implementation and operation process, and points out that the students' engineering ability includes not only the academic knowledge, but also the lifelong learning ability, team communication ability and control of large system.

Having paid close attention to the education reform trend of application-oriented talents both at home and abroad for a long time, and in combination with my own practice, since 2008 , the author and her team member ${ }^{[1-5]}$ started to study CDIO engineering education concept, and tried to implement innovative research and practice on software engineering applied talents training based on CDIO engineering education concept, undertaking a number of related research topic, having made rich research achievements in personnel training mode, curriculum system, practice teaching system and so on, won the second prize of excellent teaching achievement of Jiangsu province in 2013.

\section{QUESTIONS}

In the process of reformation, we found that traditional education mode and curriculum evaluation form were restraints to achieve practical teaching quality and improve students' practice ability, which could not be neglected. The problems that it caused were mainly as follows. 


\section{A. Professional curriculum can't ensure the quality of practice teaching}

The total class hours of talent training program and class hours of policy-type basic courses could not be compressed, because of which along with other factors, the class hours of professional courses were squeezed seriously. As a result, it was extremely difficult for teachers to complete the whole theoretical and practical parts in class and the practical part was often weakened as a price. Therefore, in the experimental course, even though teachers tried hard to instruct, it was still difficult to ensure that every student benefited from practice.

\section{B. The existing practice teaching mode is unfavorable to inspire students' potential}

Generally, traditional practical teaching acted as a supporting role to theoretical teaching. Teachers were supposed to design practical content and make an assignment before class; then students did the experiments under the instruction of teachers, after which they submitted the reports. Though some responsible teachers would check students' progresses of experiments and gave scores, they could not take into account every student because time was terribly limited. To achieve perfect teaching effect under this kind of teaching mode would largely depend on the self-consciousness of each student ${ }^{[6]}$. However, a part of students going with leisure and getting less motivated could not learn consciously on experimental course. It was obvious that such kind of practical teaching mode was not propitious to promote students' autonomous learning and activate their potentials.

\section{The single evaluation way lead to lack of emphasis}

Under the mode of traditional teaching, the final course evaluation was generally based on final examination of theoretical part. As to practical part, students were only asked to submit experiment reports on experimental courses, the scores of which were only a part of regular grades. This traditional evaluation pattern resulted in students skimping their work and plagiarizing experiment reports. Under such circumstances, there was no way to improve students' practical and innovative ability. Teachers and students both felt pity for it.

\section{REFORM TARGET AND THOUGHT}

At present, the MOOC(Massive Open Online Course) ${ }^{[7,8]}$ is rising in domestic college education, the essence of which is to switch the roles in class, focusing on improving students' abilities. As the MOOC is prevailing, Chinese traditional education mode is under huge impact ${ }^{[9]}$. Even CDIO, a representative of engineering education, has been imbued with fresh air. To solve the above problems, ensure teaching effect of practical part and improve students' engineering practical ability, the MOOC brought us precious and timely inspiration ${ }^{[10]}$.

Therefore, we undertook further research and reformation on practical teaching mode of computer-related courses, making up our minds to put the reformation of engineering education into practice. We chose one professional course of an important major as the experimental one, which was innovated by adopting the pattern of $\mathrm{O} 2 \mathrm{O}$, and setting up multi-evaluation pattern as well as interactive sessions in the light of the advanced concept of MOOC. It would help enhance students' autonomous learning ability, cooperative spirit, engineering practical ability, innovative ability and the ability to start a business.

\section{EXPLORATIONS}

\section{A. Flipping the Classroom}

To realize the reformation of computer practical teaching mode, first, the class hours of practical teaching part must be ensured. By taking the concept of MOOC as a reference and switching the roles in class, we turned the traditional teaching mode of "teacher-centered" to a new teaching mode of "student-centered and interactive learning of students and teachers". In this new mode, students watched microlectures online and finished practical tasks, and then they discussed and did practices offline, which compressed class hours of theoretical part effectively. It constructed a teaching mode of " $T$ " (the horizontal refers to discuss and the perpendicular refers to practice) in breadth and depth, raising the proportion of practical part in the whole course.

The practical teaching part included personal practice and team practice with teaching cases coming from divided real project. The personal practice was closely related to teaching chapter. Teachers assigned practical question of each chapter on schedule, which was subdivided into several subtasks. Students were required to finish every subtask in limited time and submit them to learning platform. Different score coefficients would be set up according to different periods of submission. The team practice was arranged in several weeks before the end of the class. Students were supposed to finish the practical task in cooperation, submit practical results and attend oral examination. In evaluation, personal contribution to the team would be taken into account

The change of teaching mode also put forward the new requirements to the construction of curriculum resources, including teaching plans, notes, microlectures video, courseware and reference resources, practice question bank, MOOC learning website, practice resources and so on. A series of new curriculum resources need teachers to devote more energy to design and construct, teachers should fully consider how to enable students to make full use of these teaching resources in autonomous learning, how to strengthen the interaction between teachers and students, and how to exercise their own ability to innovate.

\section{B. O2O teaching}

In traditional teaching mode, the class hours of experimental course were limited; teachers for experimental part were insufficient and instructions of teachers to students were extremely poor, which influenced the practical teaching quality. Fortunately, the appearance of MOOC helped solve the above problems effectively. We made the instruction and requirement of the experiment and the operating method of experimental platform into micro videos, which were uploaded on the learning platform. Thus students could choose 
the learning subject freely. When having knowledge of the content and requirement, they were supposed to finish personal practice in limited time, and then submit the result online. In this way, it helped transform their pressure into motivation, finishing the practical part according to their learning paces independently. When meeting problems in the process, they could also discuss with teachers or other classmates through interactive tools.

Moreover, computer-related major is one kind of engineering discipline which needs a lot of practices. It is pivotal to carry out effective monitoring to ensure the effect and quality of practical teaching when constructing the computer-related MOOC courses. The experts proposed that we should discuss on $\mathrm{O} 2 \mathrm{O}$ teaching and practical mode of computer-related courses actively to implement the education of knowledge and practice. Comparing to online practical teaching and evaluation, the team practice offline at the end of term was beneficial for face-to-face communication between teachers and students, teamwork spirit cultivation, as well as spot monitoring on practical teaching effect.

The enlightenment MOOC brings to computer courses practical teaching is just as what Doctor ChenYing said, "The success of MOOC is Making Online and Offline Connected."

\section{C. multi-evaluation}

The teaching mode based on the concept of MOOC is the mixed type, which involves factors like teacher, student, teaching content, online teaching platform and so on. In order to have a comprehensive evaluation over every factor, a new multi-evaluation system must be established, which we have already made out following the teaching evaluation principle of combining process and result evaluation, the principle of combining quantitative evaluation and qualitative evaluation, and the principle of combining self-assessment and others assessment.

It includes evaluation subjects as teacher, student and teaching manager and evaluation objects as teacher, student, online teaching platform and so on, which adopts a combinative evaluation of diagnostic evaluation, assessment evaluation, formative evaluation and summative evaluation to evaluate several aspects such as basic quality, instructional design, teaching implementation and so on, through the form of filling out rating scales and other forms, by which the multi-evaluation is realized.

In addition, using the experience of Coursera, a partner peer review network curriculum evaluation mechanism is originally created to solve the difficult problem, that is, the increase of students scale make teachers' burden of correcting students' practical operation multiply. We let the students to participate in the usual practical homework correction in each chapter, changing the students from passive ones who are evaluated into active evaluators, so that on the one hand, teachers' burden is reduced, on the other hand students' enthusiasm of participation is improved, also can let students practice operation play an exemplary role in other students. Students can get guidance from study partner and guide others, experience the joy of learning and teaching at the same time.

\section{CONCLUSION}

The unbelievable quick success of MOOC has brought a huge impact on traditional college education. Then how to blend MOOC elements with current college education effectively, especially how to foster innovative practical ability, making full advantages of MOOC are questions worth searching for. Based on foreign advanced education concepts of MOOC and teaching mode of the mixed type, we carried out a reform plan, in which we took computer-related professional course as experiment one and designed a new mode of computer practical teaching at our school. Comparing with classes in the same grade which were under the mode of traditional teaching, the teaching result of class under the reformed teaching mode was more prominent, which proved the effectiveness of the reformation preliminarily.

We will use big data technology to make research in data mining aspects, which can help teachers make in-depth analysis of the students' learning behavior, ; on the basis of which personalized guidance strategy will be set out, in order to better achieve the purpose of teaching each of the students according to their aptitude; at the same time, intelligent evaluation methods are used for the purpose of giving students the timely feedback to their learning process to supervise and urge students to adjust their status quo, making teaching evaluation to be the effective method in promoting students autonomous learning and improve their study efficiency.

\section{REFERENCES}

[1] Universities and colleges computer applied talents training mode research group. Computer science and technology professional applied talents training mode and curriculum system research in universities and colleges [M]. Beijing: higher education press, 2012. (In Chinese)

[2] Qi Shen, Yan Zhang, "Construct practice teaching system in reference to the concept of CDIO," The magazine of computer Education, vol 10,2010, pp:57-60. (In Chinese)

[3] Qi Shen, Yan Zhang, Yang Luo, " Applied undergraduate practical teaching system construction and reform," Journal of experimental technology and management, vol 10,2010, pp:36-38. (In Chinese)

[4] Qi Shen, Yan Zhang, Juan Li, "Exploration and analysis of applied undergraduate teaching staff construction in computer science and technology major," The magazine of computer Education, vol 16,2010, pp: 119-122. (In Chinese)

[5] Qi Shen, Yan Zhang, Qiuting Gu, " Scheme design of applied undergraduate engineering specialized graduation design quality control," Journal of experimental technology and management, vol 27(12),2010, pp: 167-170. (In Chinese)

[6] Lixin Li, "Teaching evaluation study on adult higher education teaching mode," Contemporary continue education, vol 31,2013, pp:24-27. (In Chinese)

[7] Ying Wang, "Massive Open Online Courses (MOOC) typical project features analysis and revelation," Remote education magazine, vol 4,2013, pp:67-75.(In Chinese)

[8] Chunsheng Yang, Qin Sun, Wei Hao, "A research on the new mode of undergraduate talents participating in innovative project," Education in Colleges and Universities of JiangSu,vol 1,2010,pp:81-83. (In Chinese)

[9] Xiaofei Xu, "Seize the opportunity of MOOC to promote computer and software engineering teaching reform," Chinese university education, vol 1,2014, pp:29-33. (In Chinese)

[10] Maosong Sun, "Looking the MOOC from the perspective of technology and research," The magazine of computer Education, vol 9,2014, pp: 2-4. (In Chinese). 